Evtyugina, A. et al. (2020). Cognitive-conceptual model for developing foreign language communicative competence in nonlinguistic university students, International Journal of Cognitive Research in Science, Engineering and Education (IJCRSEE), (8), Special issue of Current Research and Trends in Cognitive Sciences 2020, 69-77.

Original scientific paper

UDK:

Received: October, 06.2020.

Revised: November, 06.2020.

159.922.72.072-057.875

Accepted: November, 11.2020.

doi: 10.23947/2334-8496-2020-8-SI-69-77

\title{
Cognitive-Conceptual Model for Developing Foreign Language Communicative Competence in Non-Linguistic University Students
}

\author{
Alla Evtyugina ${ }^{1 *}$, Aizhanna Zhuminova² Elena Grishina ${ }^{3}$, Irina Kondyurina ${ }^{4}$, Marina Sturikova $^{4}$
}
'Department of Russian and Foreign Languages, Russian State Vocational Pedagogical University, Ekaterinburg, Russian
Federation, e-mail: alla.evtyugina@rambler.ru
2Department of Journalism and Translation, "Turan" University, Almaty, Kazakhstan, Russian Federation, e-mail: aktobedrp@mail.ru
${ }^{3}$ Department of Foreign Languages, Ural Institute of State Fire Service of EMERCOM of Russia, Ekaterinburg, Russian Federation, e-mail: GrishinaLena18@yandex.ru
${ }^{4}$ Department of Russian and Foreign Languages, Russian State Vocational Pedagogical University, Ekaterinburg, Russian Federation, e-mail: im.kon@mail.ru; Sturikova_marina@mail.ru

\begin{abstract}
This study is devoted to the foreign language communicative competence development among non-linguistic universities under-graduate students. This research covered the issue of foreign language education based on the cognitiveconceptual model for teaching English to non-linguistic university students. As the main research method, pedagogical modelling was chosen. The experiment was conducted at Russian State Vocational Pedagogical University, Ural Federal University named after the first President of Russia B.N. Yeltsin, and Ural Institute of State Fire Service of EMERCOM of Russia among 72 undergraduate students. The results of several curriculum-based tests showed that the percentage of correct determination of expressions with the context available increased from $54 \%$ to $93.2 \%$ in EG1, and from 41.9 to $85.5 \%$ in EG2. The overall students' understanding of lexical units increased by $39.2 \%$ and $43.6 \%$, respectively. The ratio of misunderstanding/understanding of speech utterances increased from 15/7 to 6/16, while the proportion of students who do not use/use various interpretation strategies changed from $8 / 14$ to $3 / 19$. The developed cognitive-conceptual methodology effectiveness for teaching foreign language communicative competence was proven. It can be applied to train students of various specialisations at different university degree levels.
\end{abstract}

Keywords: pedagogical modelling, professional activity, intercultural communication, teaching method, competence.

\section{Introduction}

Today, globalisation and informatisation are rapidly changing the world and human life. Such transformations have led to considerable shifts in the organisation of world education, changes in the educational paradigm, and in particular, in teaching a foreign language (Sinkus, 2019).

The central goal of foreign language teaching in our newly created educational environment is not just mastering the communicative skills, but the development of readiness and ability to interact with representatives of other cultures. This goal necessitates the creation of a new methodological system that takes into account the current sociocultural and educational background (Dudeney and Hockly, 2016; Kosareva et al., 2019). As a result, there is a need for the learning process to focus on an in-depth awareness of foreign cultural phenomena, as well as perception, understanding and interpretation of a foreign language message in the aggregate with linguistic and extralinguistic characteristics. Modern linguistic education should be concentrated on the formation of strategies to overcome various difficulties in foreign language communication and provide the ability to analyse and evaluate the received information, interlocutors' actions and opinions (Kuprina et al., 2019). The emergence of post-non-classical education, characterising the current educational system in Russia, is taking place against the backdrop of changes in the educational paradigm and in the way of providing educational services (Vujičić and Tambolaš, 2019). As a consequence, one may note the emergence of an educational society based on integrity, fundamentality, evolutionism, self-organisation, and human-centric ideas. The learning process is now viewed not only as preparation for a certain future activity but also as an adaptation to social life (Biserova and Shagivaleeva, 2019).

\footnotetext{
"Corresponding author: alla.evtyugina@rambler.ru
} 
Evtyugina, A. et al. (2020). Cognitive-conceptual model for developing foreign language communicative competence in nonlinguistic university students, International Journal of Cognitive Research in Science, Engineering and Education (IJCRSEE), (8), Special issue of Current Research and Trends in Cognitive Sciences 2020, 69-77.

The current study introduces the concept of 'cognitive-conceptual model.' Throughout this paper, this term will refer to an integral model focused on the formation of the multicultural personality of a student as a subject of foreign language communication. In addition, the cognitive-conceptual model is aimed at teaching students how to adequately interpret sociocultural realities in a foreign language context and communicate with a representative of another culture, while bearing in mind the peculiarities of his/her perception of the world. The novelty of this study lies in an attempt to solve complex issues of the synergy of functional characteristics of foreign language communication in connection with the development of educational paradigm, based on the perception of speech as a process carried out by neurophysiological structures (Ud Din and Akhlaq, 2019).

\section{Literature review}

In recent years, most of foreign language teaching models applied in higher educational institutions are aimed at developing certain competencies required by university curricula or education levels (bachelor's degree, master's degree, postgraduate studies) (Li and He, 2019).

Today's professionally-oriented methodologies of foreign language teaching are focused on the development of a set of skills related to the achievement of one's individual objectives (Sinkus, 2019). In the current multilingual environment, language teaching methods are responsible for delivering a particular linguistic picture of the world. This fact emphasises the importance of not just learning a language, but the formation of communicative competence (Lasekan, 2020). In the rapidly developing information society, apart from the ability to receive and process a large amount of data, a person should also possess the skills of highly organised non-linear thinking. Such thinking is characterised as a holistic and alternative vision of reality which can offer a variety of possible solutions. It provides a possibility to express doubts about the truth of the available knowledge by improving the ability to analyse, interpret, and correct one's own thoughts (Resnick, 1987).

Currently, a growing body of literature examines theoretical and practical aspects of language competence (Celce-Murcia, 2008). In the educational field, language competence is predominantly understood as the ability to carry out communication in accordance with the study program requirements, based on a set of knowledge, skills and abilities, necessary for successful interaction (Jacobson, 2020; Sergeeva, 2014).

A considerable number of research papers also investigates the structure of the language competence. In particular, Lynch (2011) describes language competence as a combination of various components. He believes that this concept includes the understanding of the peculiarities of foreign thinking patterns, awareness of various communicative scenarios, and knowledge of strategies that can help to overcome the communication difficulties. At the same time, Kecskes (2014) argues that language competence also includes such an element as the ability to correlate and interpret the events of another culture and critically assess one's own activity.

Another area of research is devoted to identifying the relationship between communicative and intercultural competences. The analysis of scientific works on this issue has revealed that many scholars tend to single out communicative competence as a separate type of intercultural competence (Deardorff, 2009; Lasekan, 2020). Communicative competence is often referred to as the ability that allows an individual to realise him/herself within the framework of a cross-cultural dialogue (Li, et al., 2017; Jacobson, 2020) and successfully communicate in the environment with different cultural context (Entwistle, 2017; Biserova and Shagivaleeva, 2019). In the meantime, intercultural competence is defined as the ability to effectively and adequately implement communicative behaviour and achieve the desired conversation outcome in the light of the specific nature of the communicative situation (Goh and Aryadoust, 2016).

The thorough analysis of various interpretations of the intercultural competence enables identifying its important characteristics. In particular, it becomes clear that intercultural competence is much broader than communicative competence. It takes into account factors that act as intermediaries in the dialogue between different linguistic consciousnesses. This difference creates a conflicting linguocultural background that requires awareness and consideration of communicants' cultural features as various strategies of communicative behaviour of representatives of different cultures are manifested the most clearly exactly in the intercultural dialogue. For this reason, the immersion into the socio- and ethnocultural context of communication is necessary for the formation of intercultural competence (Marsh, 2002). 
Evtyugina, A. et al. (2020). Cognitive-conceptual model for developing foreign language communicative competence in nonlinguistic university students, International Journal of Cognitive Research in Science, Engineering and Education (IJCRSEE), (8), Special issue of Current Research and Trends in Cognitive Sciences 2020, 69-77.

\section{Materials and Methods}

The experiment was based at Russian State Vocational Pedagogical University (Ekaterinburg, Russia), Ural Federal University named after the first President of Russia B.N. Yeltsin (Ekaterinburg, Russia), and Ural Institute of State Fire Service of EMERCOM of Russia (Ekaterinburg, Russia). The sample population included 72 undergraduate students (39 women and 33 men) in the first and second years of study majoring in:

- Ecology and Nature Management (Ural Federal University named after the first President of Russia B.N. Yeltsin);

- Technosphere safety (Ural Institute of State Fire Service of EMERCOM of Russia);

- High-tech welding (Russian State Vocational Pedagogical University).

The selection of study participants was conducted by means of placement test (Placement Test, Upstream, Enterprise), which was offered on the pre-experimental stage. The test was aimed at selecting students with minimum sufficient level of foreign language proficiency which would enable them to take part in this study. This level was recognised as B1 (Intermediate) according to the Common European Framework of Reference for Languages. However, individuals with A2 English (Pre-Intermediate) were also allowed to participate since they represent a fairly large proportion of students in non-linguistic faculties (almost half).

Since a new method and even a new teaching methodology is proposed, it was necessary that it did not overlap with the teaching methods already known to the participants, which were used in their training earlier. At the same time, the cognitive approach to learning manifests itself most effectively if the student has basic knowledge, on the basis of which he can embed new knowledge into his model of cognizable knowledge (Warner and Dupuy, 2018). The optimal choice was the participants with the minimum basic level of foreign language proficiency. For the same reason, cutting off the impact of other influences from other teaching methods and previously obtained higher knowledge in the field of English, it was decided to exclude from the sample students of specialized linguistic faculties or those who had an in-depth study of English from the beginning of their studies.

In the course of the study, the participants were offered a set of tests, which are sequentially described below in the Results section, which are included in the research group of cognitive activity in the course of applying language skills of recognition, translation, combinatorics, determination of lexical and semantic units of text, assumption that idiomatic expressions, analysis of deep understanding of phrases and expressions (Kecskes, 2014; Li and He, 2019). Specific methods of processing statistical results for every step of research and their presentation for the convenience of the reader are sequentially presented in the Results section.

During the experiment, no personal information that could be used to identify the study participants was collected, stored or used. All respondents were aware of the experiment's goal and voluntarily agreed to be involved. The statistical processing and visualisation of data were performed via Microsoft Excel spreadsheet program.

The research object was represented by the fragments of English culture-specific discourse because they reveal the sociocultural and cognitive-conceptual specifics of speech activity. As the study material, fragments of oral and speech polemics in English that contain sociocultural and contextual lexical units were used.

The study material was sampled from the Corpus of Contemporary American English. As noted by Maxom (2010), this electronic resource is a 'synchronic model' of the national language, since it reflects various manifestations of cognitive-conceptual and sociocultural characteristics of the language as well as the frequency of the use of lexical units.

The Corpus was used as a bank of examples that represent oral linguistic material of modern American English. The creation of a database of texts in the form of oral cognitive-conceptual fragments made it possible to select target lexical units based on the criteria of their frequency of use. Thus, the list of chosen lexical items comprised of ten sociocultural and contextual expressions (Soboleva and Obdalova, 2015).

The collection of empirical data included the results of students' cognitive-conceptual activity. Respondents had to categorise speech phrases by types, translate target lexical units into Russian without and with the context available, analyse a communicative situation using the cognitive-conceptual analysis method, interpret a communicative situation and compare it with similar ones in the Russian discourse.

As for the research methodology, the authors used the interview in the form of narrative communication. Such interviews were conducted after university classes in the process of the experimental 
training and during the classes after its end. As data collection tools, specially designed tasks, data of pedagogical observations, results of the surveying of involved students and teachers, and content analysis were used.

\section{Results}

First of all, study participants were offered a categorisation task based on the visual perception of target lexical units in a text fragment. It allowed determining the manifestation of students' cognitive abilities while classifying English phrases. The pie chart in Figure 1 exposes that the greatest difficulty was in categorising situation-bound utterances (SBUs). The percentage of incorrect determination of SBUs constituted 60\%; fixed semantic units (FU) - 24\%; and idiomatic expressions (ID) $-17 \%$.

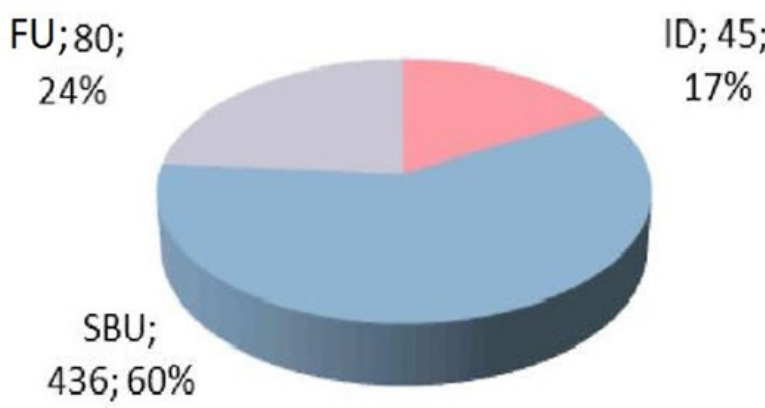

Figure 1. Percentage of errors in the categorisation of lexical units

The obtained empirical data confirmed the assumption that idiomatic expressions, as bright and emotionally coloured phrases, are easier to remember and identify among other lexical units. Tasks 2 and 3 were carried out on the basis of an authentic foreign language context and supposed its auditory perception. In the second test, students were required to understand the meanings of ten situational expressions. In the third test task, the cognitive-conceptual and intercultural-communicative aspects of students' activities were assessed according to the parameters of understanding/misunderstanding, depth of understanding, and management of individual speech-thinking activity (the ability to link a concept to native culture and personal life experience).

In order to examine the cognitive-conceptual aspect of students' speech and thinking activity, this study compared the frequency of the use of strategies to interpret the meanings of lexical units and communicative situations on the example of expressions under consideration. The investigation revealed that the percentage of correct determination of expressions with the context available increased significantly - from $54 \%$ to $93.2 \%$ in EG1, and from 41.9 to $85.5 \%$ in EG2. Thus, the overall students' understanding of lexical units increased by $39.2 \%$ and $43.6 \%$, respectively. As a consequence, it can be asserted that the provision of situational context increased the quality of perception, thereby contributing to the analysis and synthesis of all the semantic properties of a linguistic unit (Figure 2).

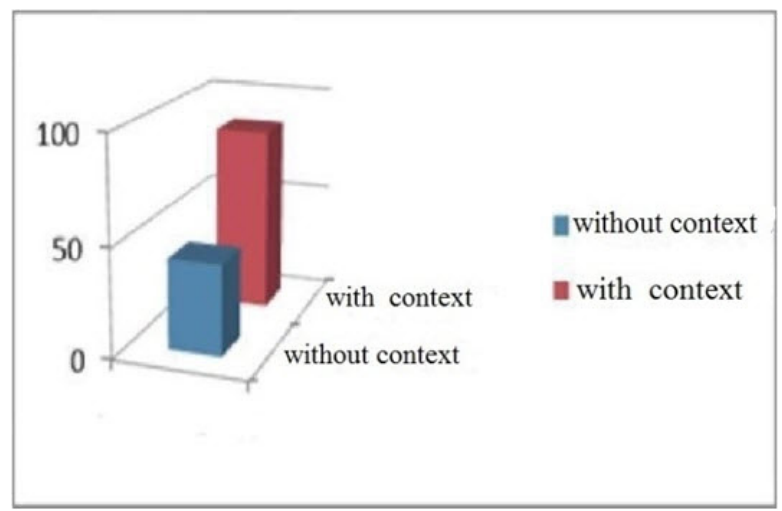

Figure 2. Improvement in understanding a lexical unit depending on the context availability

The analysis of the depth of understanding parameter showed that students' application of the strategy of meaning extraction based on literal translation did not allow revealing the implicit meaning of a 
holistic phrase (Goswami and Bryant, 2007). Such individuals failed to realise the meaning of the phrase even though they could translate all the words in it.

As the study showed, most respondents had no idea about the different characteristics of the context and diverse ways of expressing standard speech formulae in English. The analysis of students' notes showed that the majority of examination participants relied predominantly on the literal meanings of words. Figures 3 and 4 show the ratio of students' correct and incorrect interlingual translations of situational expressions with and without the context available.

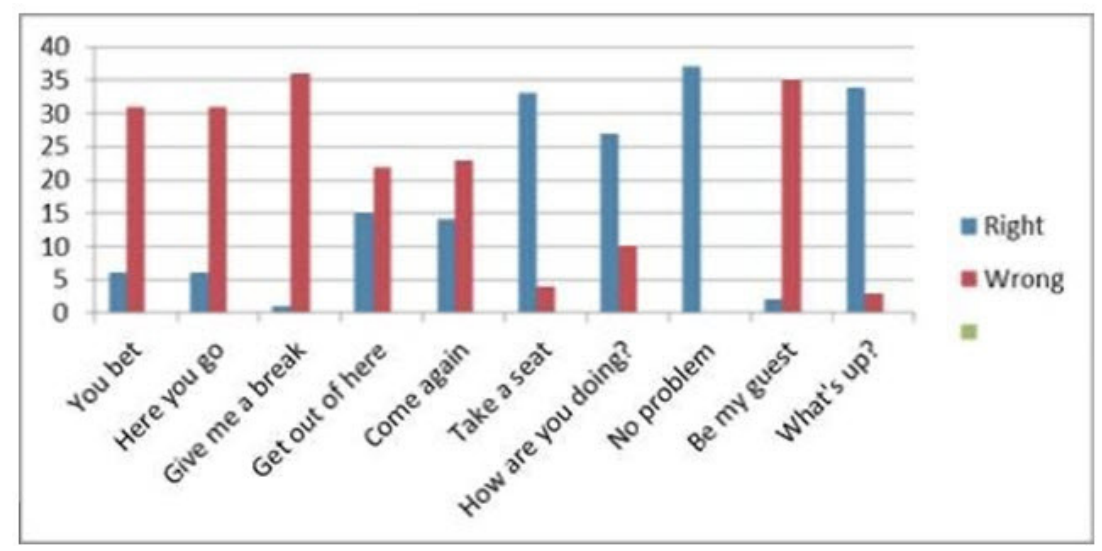

Figure 3. Correlation between correct and incorrect interpretations of situational expressions without the context available (for EG2)

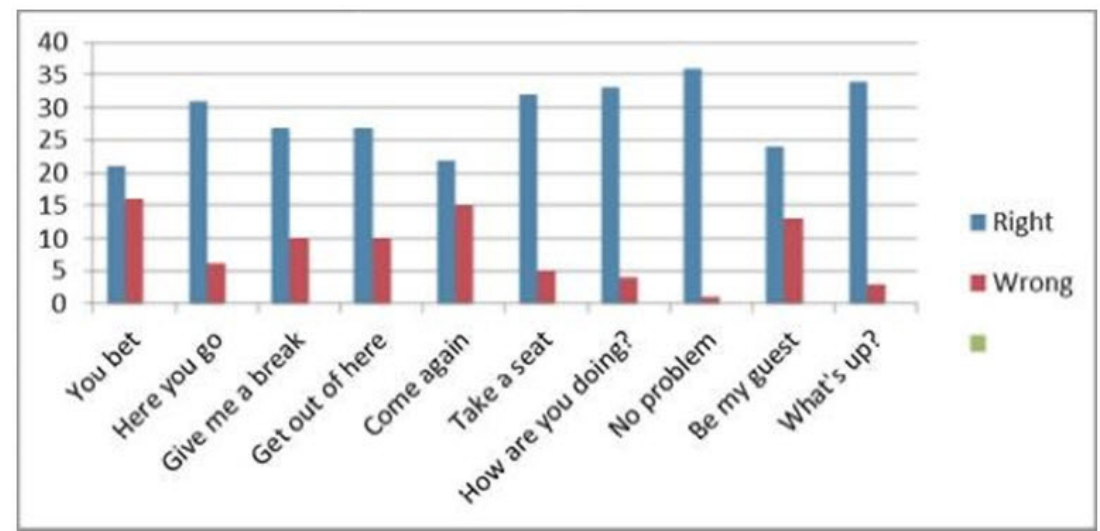

Figure 4. Correlation of correct and incorrect interpretations of situationally conditioned expressions with the context available (for EG2)

For a comprehensive assessment of the formation of foreign language communicative competence according to the cognitive-conceptual aspect of foreign language activity, the method of complex assessment was applied (modified methodology of Tobias and Everson (2002)).

Based on the formula for calculating the coefficient of communicative competence $(E)$, one can get the value $E=1$ when the student is successful in all the selected parameters of foreign language activity (indicators $a$ and $b$ have $a$ ' + ' sign). This indicates that the one understands the context at the semantic level and relies on a set of effective strategies for foreign language speech interpretation. The value $E=$ -1 is obtained when the student does not demonstrate the understanding of the text and flexibility in the use of speech strategies (indicators $c$ and $d$ have $a$ '-' sign). The value $E=0$ can be achieved only in case of equal numbers of successful and unsuccessful manifestations of the parameters of communicative and cognitive-conceptual activity (c and d).

To demonstrate the technique of complex assessment of the formation of foreign language communicative competence in terms of the cognitive-conceptual aspect, the authors of the current study applied it on 22 individuals from EG1. The corresponding data were based on the analysis of students' test results and were collected at the beginning and at the end of the experimental work. In such a manner, at the beginning of the training, 5 students out of 22 had a 'zero' level of competence - they neither understood the content of the utterances nor used meaning extraction strategies. In the meantime, by the end of the experiment, only one person was described as such. Furthermore, at the beginning of 
the experimental work, 10 students out of 22 did not achieve an understanding of the implicit meaning of the lexical unit but understood the general meaning of the communicative situation without the use of interpretation strategies. In this respect, it was noted that only 5 students had such a result after the experiment finished. As for those who managed to extract the meaning of a speech utterance, but did not use various interpretation strategies, only 3 such students were noted before the experimental training, and 2 after its end. A situation, when one of the considered skills was not developed, designates a low level of language competency. Out of 22 individuals, 14 successfully interpreted the meaning of a lexical unit and demonstrated good discourse analysis skills (compared to 4 students before the experiment started). As a result, the given data indicate that the performed experimental training provided the possibility to increase the level of English language competence.

The ratio of misunderstanding/understanding of speech utterances increased from 15/7 to 6/16, and the ratio of non-using/using various interpretation strategies increased from 8/14 to 3/19.

Figure 5 depicts the dynamics of the formation of foreign language communicative competence among undergraduate students from EGs as a result of the approbation of the cognitive-conceptual model of teaching. The radial diagram demonstrates a significant improvement in students' language competence according to the five parameters. The external figure, reflecting their values at the end of the experiment, is much larger than the internal one corresponding to the beginning of training, showing increments of up to $80 \%$ or more.

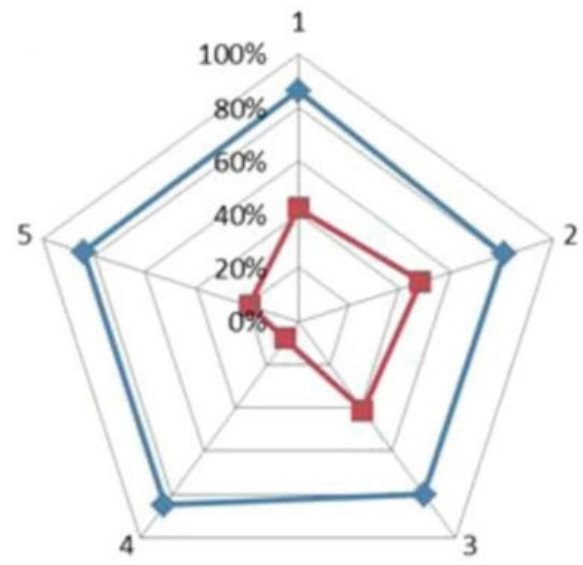

Figure 5. Dynamics of the formation of foreign language communicative competence (\%)

Diagnostic parameters:

1 - understanding of professionally-oriented texts;

2 - use of professional vocabulary;

3 - speech activity;

4 - understanding of socio-culturally marked realities;

5 - variability of the strategies used for foreign speech interpretation.

At the final stage of the experiment, students' levels of formation of the foreign language communicative competence were assessed based on the results of the control task fulfilment. The interpretation of the results obtained made it possible to draw a conclusion about the positive dynamics of the development of foreign language communicative competence in the experimental and control groups. The level of understanding culturally marked lexical units changed from $62 \%$ and $68 \%$ to $92 \%$ and $94 \%$ in the EG1 and EG2, respectively, and from $64 \%$ to $68 \%$ in the CG. In the meantime, the level of competence in professionally-oriented discourse increased from $82 \%$ and $77 \%$ to $92 \%$ and $94 \%$ in EG1 and EG2, respectively, and from $86 \%$ to $88 \%$ in CG. Given the collected data, it may be argued that the observed positive dynamics resulted from the application of the developed cognitive-conceptual training model.

\section{Discussion}

Modelling as a research method came to pedagogy from mathematics and cybernetics and significantly expanded the ability of teachers to obtain better representations of examined objects (CelceMurcia, 2008; Jacobson, 2020). Researchers identify many ways of modelling depending on the object itself and the level of its abstraction (macro- or micro-level) (Jacobson, 2020). The model of the education 
system is represented in the macro-level as it sets learning goals and trajectories depending on social needs and principles of adopted state policy. The model of the learning process can be presented in the micro-level as a theoretical structure described by means of didactic and methodological categories (Vujičić and Tambolaš, 2019). Pedagogical modelling is believed to reflect the characteristics of the 'existing education system' (Traxler, 2018). Its most critical characteristics include the integrity of the processes, availability of information describing them, and structural interconnection of the elements of the model (Oudeyer et al., 2016).

In the course of research activities, scholars have identified four types of learning models based on the prevailing components of the course content and student's learning objectives: linguistic, communicative, professionally-oriented, and competence-oriented (Dudeney and Hockly, 2016). Linguistic models are also divided into two types - models aimed at teaching the lexical or grammatical aspect of language (Lewis et al, 1997). The emphasis on the lexical side of training correspondingly develops student's lexical competence. This modelling type touches upon the way of presenting material, describes the desired result of a conversation 'in the form of blocks of lexical units,' and concentrates on verbal language. Correspondingly, grammatically-centred models of students' training focus on grammar. Nowadays, in the modern language learning models, the study of lexical and grammatical aspects is combined and corresponds to changes in students' educational goals, future professional orientation, and learning strategies.

The study of the structure of understanding a foreign language and the formation of language competence as the ability of its contextual use is especially relevant for South and South-East Asia. Historically, in these regions, English and other European languages have become the basis for cultural and economic modernisation as well as a means of everyday communication (Ud Din and Akhlaq, 2019 ). The communication model of this region is traditionally based on studying a significant amount of texts and other paper materials to accumulate a large number of lexical units before coming into direct contact with a native speaker (Srinivasan, 2018).

In a number of regions of the world, foreign language teachers act as central communicators and authoritative sources in linguistic matters. They have the same features of professional foreign language communicative competence, as identified in the current study (first of all, the understanding of foreign language texts and fluent use of professional vocabulary) (Suryani et al., 2020). In most countries of Western Europe and the USA, according to research results, the domestic and personal cultural aspects of communication competence prevail (Li et al., 2017).

Modern communication models are focused on satisfying student's needs for foreign language activity. Their aim is to teach how to express one's thoughts and provide an understanding of the original foreign-language message. Among foreign methodologists, one of the most accurate descriptions of the communicative approach principles is given by Rivers (1983). She has formulated the task of teaching a foreign language as the ability to apply the acquired communication skills by means of the target language. Such a communication-oriented approach presupposes the use of the principles of personal involvement, meaningful communication, and students' interaction in the process of educational activity.

In accordance with the communicative approach, the language learning process should take into account the peculiarities of real conversation. New models of teaching students are guided by the correspondence of the course material to the real interaction between specialists in a certain area of activity. Such models of teaching, being built on the cognitive-conceptual approach, are implemented in the form known as '(English) language for specific purposes' in various modifications (LSP, ESP, CLIL, etc.) (Daokuan, 2016).

The latest professionally-oriented models of language learning imply the formation of students' ability to communicate in a foreign language against the background of their occupation and through language immersion and content-based instruction (Evdokimova, 2017; Li et al., 2017). A good example of such a methodology can be Content and Language Integrated Learning (CLIL). The term CLIL was created by Marsh (2002) to denote a set of methods for studying the non-linguistic discipline, for instance, Math, using language as the means of education. His methodology is built with reference to the needs of students, based on which the content and methods of teaching are determined. Consequently, CLIL learning methodology pursues a double goal - the simultaneous study of the discipline and the foreign language (Marsh, 2002).

\section{Conclusions}

The results of the conducted experiment showed that the indicators of the level of formation of foreign 
language communicative competence among the EG respondents, trained according to the cognitiveconceptual model, were higher than those of CG students. The percentage of correct determination of expressions with the context available increased significantly - from $54 \%$ to $93.2 \%$ in EG1, and from 41.9 to $85.5 \%$ in EG2. Thus, the overall students' understanding of lexical units enhanced by $39.2 \%$ and $43.6 \%$, respectively. The ratio of misunderstanding/understanding of speech utterances increased from $15 / 7$ to $6 / 16$, while the proportion of students who do not use/use various interpretation strategies changed from $8 / 14$ to $3 / 19$. An increase in the number of strategies used and an increase in the flexibility of thinking lags somewhat behind the level of success in solving practical problems of language understanding.

Within the framework of the present study, it was proved that the positive dynamics in the development of foreign language communicative competence resulted from the enhancement and upgrade of the learning process and training content. The developed methodological system was based on three unique elements: cognitive-conceptual learning, personal learning model, and newly-created teaching methodology. Their synergy laid down a didactic base that contributes to the effective achievement of a new goal of teaching undergraduate students - fluent foreign language communication. The focus of a new teaching methodology, the effectiveness of which has been demonstrated by the results of the experiment, is based not only on the individualization of the learning path, but on cognitive rather than memorizing and repetitive activities during the course of learning.

Based on the analysis of criteria and indicators of training success, this research experimentally confirmed the effectiveness of the cognitive-conceptual learning model. In addition, it was uncovered that the introduction of the proposed training methodology facilitates the formation of a basic level of intercultural competence among students.

The practical significance of this study lies in the possibility of introducing the developed cognitiveconceptual model of teaching foreign language communicative competence into the higher educational institutions' pedagogical practice. Further research in this field will be concentrated on the more detailed development of the methodological provisions of cognitive-conceptual approach and their sub-sequent implementation in scientific, methodological and practical activities.

The results of the research are suggested to be used as a basis for the development of new curricula for the development of the communicative competence of foreign languages. It is also proposed to expand research on the application of the cognitive-conceptual approach to other fields of education.

\section{Acknowledgments}

The authors are grateful to the reviewers' and editors' valuable comments that improved the manuscript.

\section{Conflict of interests}

The authors declare no conflict of interest.

\section{References}

Biserova, G. K., \& Shagivaleeva, G. R. (2019). Socio-psychological adaptation of international students to learning and professional activities. Space and Culture, India, 6(5), 99-114. https://doi.org/10.20896/saci.v6i5.411

Celce-Murcia, M. (2008). Rethinking the role of communicative competence in language teaching. In Intercultural language use and language learning (pp. 41-57). Springer, Dordrecht. https://doi.org/10.1007/978-1-4020-5639-0_3

Daokuan, H. (2016). Jieshao yimen xinxing kexue — kuawenhua de jiaoji. Waiguo yuyan yu wenxue, 2, 70-73.

Deardorff, D. K. (2009). The Sage handbook of intercultural competence. Sage.

Dudeney, G., \& Hockly, N. (2016). How to Teach English with Technology. Pearson Education Limited.

Dunn, J. (2016). Computational learning of construction grammars. Language and cognition, 9(2), 254-292. https://doi. org/10.1017/langcog.2016.7

Entwistle, J. (2017). Emotional labour. In D. Richardson (Ed.), The International Encyclopedia of Geography: People, the Earth, Environment and Technology (pp. 1-3). Wiley-Blackwell. https://doi.org/10.1002/9781118786352.wbieg0313

Entwistle, N., \& Ramsden, P. (2015). Understanding student learning (Routledge revivals). Routledge.

Evdokimova, M. G. (2017). Innovative system of professionally oriented foreign language teaching in a non-linguistic university. Biblio-Globus Publ.

Goh, C. M., \& Aryadoust, V. (2016). Learner listening: New insights and directions from empirical studies. International Journal of Listening, 30(1-2), 1-7. https://doi.org/10.1080/10904018.2016.1138689

Goswami, U., \& Bryant, P. (2007). Children's cognitive development and learning. University of Cambridge.

Jacobson, M. J. (2020). Complexity conceptual perspectives for research about educational complex systems. The Journal of Experimental Education, 88(3), 375-381. https://doi.org/10.1080/00220973.2019.1652138 
Evtyugina, A. et al. (2020). Cognitive-conceptual model for developing foreign language communicative competence in nonlinguistic university students, International Journal of Cognitive Research in Science, Engineering and Education (IJCRSEE), (8), Special issue of Current Research and Trends in Cognitive Sciences 2020, 69-77.

Kecskes, I. (2014). Evaluative function of situation-bound utterances. In G. Thompsom \& L. Alba-Juez (Eds.), Evaluation in Context (pp. 137-150). John Benjamins Publishing Company. Retrieved from https://languageofevaluation.info/ seminar1/wp-content/uploads/2019/03/Thompson-Alba-Juez_ed.-Evaluation-in-Context.pdf\#page=150

Kosareva, L., Evreeva, O., \& Zakirova, O. (2019). Formation of language competence: Modern issues and strategies in the area of cross-cultural communication. Space and Culture, India, 7(3), 149-159. https://doi.org/10.20896/saci.v7i3.525

Kuprina, T. V., Beketova, A. P., \& Minasyan, S. M. (2019). Self-organising systems in the context of academic environment. The Education and Science Journal, 21(1), 150-166. https://doi.org/10.17853/1994-5639-2019-1-150-169

Lasekan, O. (2020). Using the Interpersonal Relationship Communication Approach to Assess Language Dominance in both Written and Oral Communication among Multilinguals. Space and Culture, India, 8(1), 164-176. https://doi. org/10.20896/saci.v8i1.623

Lewis, M., Gough, C., Martínez, R., Powell, M., Marks, J., Woolard, G. C., \& Ribisch, K. H. (1997). Implementing the lexical approach: Putting theory into practice, 3(1), 223-232. Hove: Language Teaching Publications. Retrieved from http:/l www.tesl-ej.org/wordpress/issues/volume3/ej09/ej09r10/?wscr

$\mathrm{Li}$, Y., \& He, Z. (2019). Environmental Adaptation Theory and application in Standard Language Competence Model. Ekoloji, 28(107), 2779-2782. http://ekolojidergisi.com/download/environmental-adaptation-theory-and-application-in-standardlanguage-competence-model-5910.pdf

Li, Y., Yang, X., \& Cheng, L. (2017). The enlightenment of specialised foreign language talents training in the US to our country. Journal of Anshan Normal University, 1, 11. http://en.cnki.com.cn/Article_en/CJFDTotal-ASSF201701011.htm

Lynch, T. (2011). Academic listening in the 21st century: Reviewing a decade of research. Journal of English for Academic Purposes, 10(2), 79-88. https://doi.org/10.1016/i.jeap.2011.03.001

Marsh D. (2002). Content and Language Integrated Learning: The European Dimension - Actions, Trends and Foresight Potential. Oxford Univ. Press.

Maxom, M. (2010). Teaching English as a foreign language for dummies. John Wiley \& Sons.

Oudeyer, P. Y., Gottlieb, J. \& Lopes, M. (2016). Intrinsic motivation, curiosity, and learning: Theory and applications in educational technologies. Progress in brain research, 229, 257-284. https://doi.org/10.1016/bs.pbr.2016.05.005

Resnick, L. B., \& Science National Research Council (US). Committee on Research in Mathematics. (1987). Education and learning to think. National Academy Press.

Rivers, W. M. (1983). Communicating naturally in a second language: Theory and practice in language teaching. Cambridge University Press.

Sergeeva, N. N. (2014). Foreign language communicative competence in the field of professional activity: Model and method development. Procedia-Social and Behavioral Sciences, 154, 250-253. https://doi.org/10.1016/j.sbspro.2014.10.145

Sinkus, T. (2019). The Development of Professional English Language Competence in Business Administration Studies. Rural Environment. Education. Personality. (REEP), 12, 173-181. https://doi.org/10.22616/REEP.2019.022

Soboleva, A. V., \& Obdalova, O. A. (2015). Strategies in interpretation of culture-specific units by Russian EFL students. Procedia-Social and Behavioral Sciences, 200, 69-76. https://doi.org/10.1016/j.sbspro.2015.08.016

Srinivasan, R. T. (2018). Introduction: South Asia from Postcolonial to World Anglophone. Interventions, 20(3), 309-316. https:// doi.org/10.1080/1369801X.2018.1446840

Suryani, A., Soedarso, S., Diani, K. T. \& Rosmawati, R. (2020). English teaching in social and cultural contexts: Language teachers as cultural managers. LLT Journal: A Journal on Language and Language Teaching, 23(2), 273-292. http:/l dx.doi.org/10.24071/llt.v23i2.2470

Tobias, S., \& Everson, H. T. (2002). Knowing what you know and what you don't: further research on metacognitive knowledge monitoring: research report 2002-3. College Entrance Examination Board. https://files.eric.ed.gov/fulltext/ED562778. pdf

Traxler, J. (2018). Current State of Mobile Learning. In M. Ally (Ed.), Mobile Learning: Transforming the Delivery of Education and Training (pp. 9-25). AU Press.

Vujičić, L., \& Tambolaš, A. C. (2019). Educational Paradigm and Professional Development: Dimensions of the Culture of Educational Institution. In J. Lepičnik Vodopivec, L. Jančec, \& T. Štemberger (Eds.), Implicit Pedagogy for Optimised Learning in Contemporary Education (pp. 77-103). IGI Global. https://doi.org/10.4018/978-1-5225-5799-9.ch005

Ud Din, K., \& Akhlaq, M. W. (2019). Influence of English Language in Political Awareness of South Asian Societies: A Comparative Study of India, Pakistan and Bangladesh. South Asian Studies, 34(1), 213-225. Retrieved from http://111.68.103.26/ journals/index.php/IJSAS/article/view/3236

Warner, C., \& Dupuy, B. (2018). Moving toward multiliteracies in foreign language teaching: Past and present perspectives... and beyond. Foreign Language Annals, 51(1), 116-128. https://doi.org/10.1111/flan.12316 
Evtyugina, A. et al. (2020). Cognitive-conceptual model for developing foreign language communicative competence in nonlinguistic university students, International Journal of Cognitive Research in Science, Engineering and Education (IJCRSEE), (8), Special issue of Current Research and Trends in Cognitive Sciences 2020, 69-77. 